\title{
In vitro cultivation of Gigaspora decipiens using transformed roots of Linum usitatissimum
}

\author{
Dhillan, M. Velip and B. F. Rodrigues* \\ Department of Botany, Goa University, Goa 403206 \\ *Corresponding authorEmail:felinov@gmail.com
}

(Submitted on November 12, 2019; Accepted on December 17, 2019)

\section{ABSTRACT}

\begin{abstract}
Symbiosis between arbuscular mycorrhizal fungi (AMF) and higher plants provides a wide scope for its use as biofertilizer. Mass multiplication of pure AMF cultures however, has always been a challenge. Use of transformed roots for the establishment of monoxenic cultures of AMF is being done in recent years but with a low success rate with regard to spore production in vitro. The present study exhibits a successful attempt towards in vitro culturing and sporulation of Gigaspora decipiens Hall \& Abbott in transformed roots of Linum usitatissimum L. (Flax) Also, the present study describes a technique wherein spore germination and in vitro root colonization can be brought about in the same Petri plate rather than transferring a prior germinated AM spore among the T-DNA roots. This technique minimizes the effect of relocation of germinating spores thereby hastening root colonization.
\end{abstract}

KEYWORDS: Sporulation, culturing, AMF, monoxenic culture, transformed roots

\section{INTRODUCTION}

Arbuscular mycorrhizal fungi (AMF) are one of the most abundant groups of symbiotic organisms. They are involved in supplying nutrients to about $80 \%$ of terrestrial plants thereby improving their growth and vigour (Smith and Read, 2008). This feature projects AMF as high potential candidates for use as biofertilizers.

The glitch in use of AMF as biofertilizers lies in the fact that they are obligatory biotrophs. They cannot be grown or multiplied on artificial medium. Researchers have found a solution to this difficulty through development of monoxenic cultures using in vitro grown transformed roots as a symbiotic partner for AMF (Bécard and Fortin, 1988; Mosse and Hepper, 1975; Fortin et al., 2002). Monoxenic cultures of AMF so developed ascertains purity of the cultures and enables continuous monitoring of the colonies to observe mycelial development and spore initiation and maturation (Tahir, 2003; Pawlowska et al., 1999; Akimaya et al., 2005; Calvet et al., 2013; Voets et al., 2009). More importantly it helps in molecular, physiological and taxonomic studies of the AMF species (Croll et al., 2008; Kokkoris and Hart, 2019; Luginbuehletal., 2017).

This technique is however, in its infancy with not many species of AMF in culture. Also few of the cultures have difficulty in sporulating in vitro (Karandashov et al., 2000). The few strains that have been successfully brought into monoxenic cultures mainly belong to the genera Glomus and Gigaspora. One or more strains of Scutellospora and Acaulospora have also been cultured in vitro (Dalpé and Declerck, 2002; de Souza and Declerck, 2003). Researchers have identified humidity, light, $\mathrm{CO}_{2}$, temperature and $\mathrm{pH}$ as some of the important physical factors while substrate composition and nutrient availability as the nutritional factors involved in successful establishment of monoxenic cultures (Bécard et al., 1992; Maia and Yano-Melo, 2001). Besides, factors such as presence of root exudates or contaminants have also been found to significantly affect growth and sporulation of AMF in monoxenic cultures.

The present study was aimed to establish a monoxenic culture of Gigaspora decipiens in transformed roots of
Linum usitatissimum L. and to induce sporulation in them (Fig. 1: a-l).

\section{MATERIAL AND METHODS}

Source of AMF: Rhizosphere soil associated with Vigna unguiculata (L.) Walp. collected from agriculture fields was selected as source of AMF. Spores of AMF were isolated using the wet sieving and decanting technique (Gerdemann and Nicolson, 1963). Among the isolated species, Gi. decipiens was dominant.

Further, the spores of Gi. decipiens were multiplied through trap culture in Coleus plant [Plectranthus scutellarioides (L.) R.] in the polyhouse (Goa University Arbuscular Mycorrhizal Culture Collection (GUAMCC)). The plants were grown in pots containing sterilized sand and maintained under controlled polyhouse conditions $\left(25^{\circ} \mathrm{C}\right.$, RH $\left.80-90 \%\right)$ for 45 days.

Development of monoxenic cultures: Gi. decipiens spores extracted from the trap culture were carefully picked using a stereomicroscope. Under aseptic conditions, the isolated spores were rinsed twice in sterile distilled water and disinfected in $250 \mu \mathrm{L}$ sodium hypochlorite for 5 minutes. This was followed by triple rinsing with sterile distilled water. The spores were finally rinsed in streptomycin sulfate $(0.02 \%$ w/v) for 10 minutes (Mosse, 1959; Bécard and Fortin, 1988).

Modified Strullu Romand (MSR) medium (pH 6.5) was prepared with and without sucrose. Petri plates were poured with MSR medium with sucrose and allowed to solidify in a slanting position. This was overlayed with a thin layer of MSR medium without sucrose such that part of the MSR medium with sucrose still remained exposed on the surface. Surface-sterilized spores were inoculated on these plates for germination. They were placed in the region of the Petri plate which had MSR medium without sucrose. The Petri plates were incubated in an inverted position in dark at $27^{\circ} \mathrm{C}$ and monitored daily under a stereomicroscope for germination. The T-DNA transformed roots of $L$. usitatissimum were procured from Prof. Stéphane Declerck, Mycothèque de l'Université Catholique de Louvain (MUCL), Belgium.

Once germination was observed, an actively growing 


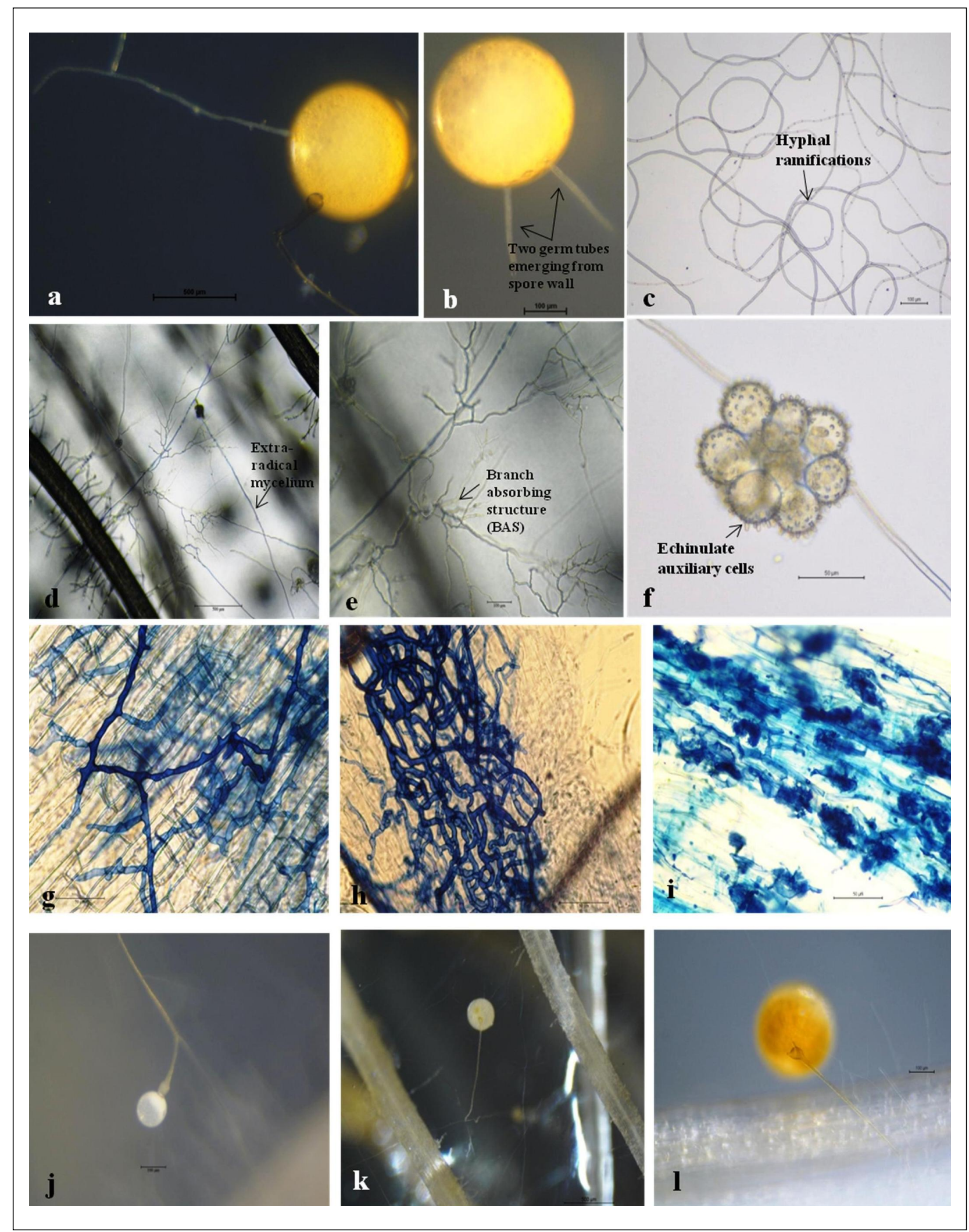

Fig. 1: In vitro culture of Gigaspora decipiens. a, b. spore germination; c. hyphal ramifications; d. extra-radical mycelium; e. branched absorbing structures (BAS); f. auxiliary cells; g, h. hyphal colonization; i. arbuscules; j-k. sporulation showing juvenile spores, $\mathbf{l}$. mature spore. 
transformed root of L. usitatissimum with several lateral branches was placed in the vicinity of the germinated spore in the Petri plate which had MSR medium with sucrose. The Petri plates were then again incubated in an inverted position in the dark at $27^{\circ} \mathrm{C}$ and monitored after every 4 days under the stereomicroscope for colonization followed by sporulation. After 45-50 days, the roots were stained with trypan blue (Phillips and Hayman, 1970; Giovannetti and Mosse, 1980) to observe root colonization. Spore production of Gi. decipiens was evaluated on weekly basis under a stereomicroscope over a period of 6 months.

\section{RESULTSAND DISCUSSION}

In vitro spore germination in Gi. decipiens was recorded within 3 days of plating on MSR medium which showed emergence of multiple germ tubes (Fig. 1: a, b). In an earlier study, Costa et al., (2013) reported spore germination in Gi. decipiens after 4-5 days.

After 20-25 days of incubation, hyphae grew throughout the Petri plate and developed hyphal ramifications, abundant extra-radical mycelia, branched absorbing structures (BAS) and auxiliary cells (Fig. 1: c-f). These various hyphal structures were also observed by earlier workers (Maia and Yano-Melo, 2001; de Souza et al., 2005; Costa et al., 2013) and were probably formed in response to environmental or nutritional stimulation (Bécard and Fortin, 1988; Bago et al., 1998b). It has also been suggested that these structures, particularly the BAS, increase the contact surface of the fungus with the culture medium thereby improving its nutrient absorption rate (Bago et al., 1998a). An increased number of BAS by a particular strain suggests its ability of better absorption of the nutrients and thereafter its enhanced delivery to its co-symbiont, the plant and improved plant growth rate. Owing to its high BAS formation, the present strain has a potential to be considered as a candidate for biofertilizer inoculum production.

The germ tubes grew and branched in direction of the transformed roots. The hyphal branching in the culture medium exhibited two patterns of growth, viz. apical and lateral. The lateral branches showed the presence of septa. The hyphae successfully colonized the transformed Linum roots after 45 days. The hyphal colonization was dense as evident through trypan blue staining (Fig.1: g, h). The hyphae penetrated the cells to form arbuscules Fig.1: i). Since, both the spore and transformed roots were inoculated on the same Petri plate in regions containing MSR medium without and with sucrose, respectively, the effect of relocation of germinating spores was minimized, thereby speeding root colonization.

Sporulation was observed after 50 to 55 days of growth (Fig.1: j-l). On an average 5 spores were observed per Petri plate. This is a significant step in in vitro culture of AMF as this step is essential to scale up AMF inoculum production (Declerck et al., 2001; Ijdo et al., 2011). The ability of $\mathrm{Gi}$. decipiens strain under study to sporulate within 2 months of inoculation is yet another highly promising step towards considering the strain for biofertilizer inoculum production.

\section{CONCLUSION}

The monoxenic culture of Gi. decipiens was successfully established in transformed root of L. usitatissimum L. Further the culture produced BAS and spores which are highly desirable characters in considering an AMF strain for biofertilizer inoculum production. This culture is therefore being further developed as inocula for its application as biofertilizer.

\section{ACKNOWLEDGEMENTS}

Authors gratefully acknowledge the financial assistance received from the Department of Science, Technology and Environment (DSTE), Government of Goa, to carry out this study.

\section{REFERENCES}

Akiyama, K., Matsuzaki, K. and Hayashi, H. 2005. Plant sesquiterpenes induce hyphal branching in arbuscular mycorrhizal fungi. Nature. 435: 824827. doi: $10.1038 /$ nature03608.

Bago, B., Azcon-Aguilar, C., Goulet, A. and Piché, Y. 1998a. Branched absorbing structures (BAS): a feature of the extraradical mycelium of symbiotic arbuscular mycorrhizal fungi. New Phytol. 139: 375-388.

Bago, B., Azcon-Aguilar, C. and Piché, Y. 1998b. Architecture and developmental dynamics of the external mycelium of the arbuscular mycorrhizal fungus Glomus intraradices grown under monoxenic conditions. Mycologia 90: 52-62.

Bécard, G. and Fortin, A. 1988. Early events of vesicular arbuscular mycorrhiza formation on $\mathrm{Ri}$ T-DNA transformed roots. New Phytol. 108: 211-218.

Bécard, G., Douds, D.D. and Pfeffer, P.E. 1992. Extensive in vitro hyphal growth of vesicular-arbuscular mycorrhizal fungi in the presence of $\mathrm{CO}_{2}$ and flavonols. Appl. Environ. Microbiol. 58: 821-825.

Calvet, C., Camprubi, A., Pérez-Hernández, A. and Lovato, P.E. 2013. Plant growth stimulation and root colonization potential of in vivo versus in vitro arbuscular mycorrhizal inocula: Ameri. Soc. Hort. Sci. http://hortsci.ashspublications.org/content/ 48/7/897.short.

Costa, F.A., Haddad, L.S.M., Kasuya, M.C.M., Oton, W.C., Costa, M.D. and Borges, A.C. 2013. In vitro culture of Gigaspora decipiens and Glomus clarum in transformed roots of carrot: the influence of temperature and pH. Acta Sci. Agron. 35: 315-323. doi: 10.4025 /actasciagron.v35i3.16581.

Croll, D., Corradi, N., Gamper, H.A. and Sanders, I.R. 2008. Multilocus genotyping of arbuscular mycorrhizal fungi and marker suitability for population genetics. New Phytol. 180: 564- 568. doi: 10.1111/j.14698137.2008.02602.x

Dalpé, Y. and Declerck, S. 2002. Development of Acaulospora rehmii spore and hyphal swellings 
under root-organ culture. Mycologia 94: 850-855. doi: $10.1080 / 15572536.2003 .11833178$.

de Souza, F.A. and Declerck, S. 2003. Mycelium development and architecture, and spore production of Scutellospora reticulata in monoxenic culture with Ri T-DNA transformed carrot roots. Mycologia 95: 1004-1012. Doi: 10.1080/15572536.2004.1183 3016.

de Souza, F.A., Declerck, S., Smith, E. and Kowallchuk, G.A. 2005. Morphological, ontogenetic and molecular characterization of Scutellospora reticulata (Glomeromycota). Mycol. Res. 109: 697-706.

Declerck, S. D'Or D., Cranenbrouck, S.L.E. and Boulenge, E. 2001. Modelling the sporulation dynamics of arbuscular mycorrhizal fungi in monoxenic culture. Mycorrhiza 11: 225-230.

Fortin, J.A., Bécard, G., Declerck, S., Dalpé, Y., St-Arnaud, M., Coughlan, A.P. and Yves, Piché. 2002. Arbuscular mycorrhiza on root-organ cultures. Can. J. Bot. 80: 1-20. doi: 10.1139/b01-139.

Gerdemann, J.W. and Nicolson, T.H. 1963. Spores of mycorrhizal Endogone species extracted from soil by wet sieving and decanting. Trans. Bri. Mycol. Soc. 46: 235-244.

Giovannetti, M. and Mosse, B. 1980. An evaluation of techniques for measuring vesicular arbuscular mycorrizal infection in roots. New Phytol. 84: 489500.

Ijdo, M., Cranenbouck, S. and Declerck, S. 2011. Methods for large-scale production of AM fungi: past, present and future. Mycorrhiza 21: 1-16.

Karandashov, V., Kuzovkina, I., Hawkins, H.J. and George, E. 2000. Growth and sporulation of the arbuscular mycorrhizal fungus Glomus calendonium in dual culture with transformed carrot roots. Mycorrhiza 10: $23-28$.

Kokkoris, V. and Hart, M.M. 2019. The role of in vitro cultivation on symbiotic trait and function variation in a single species of arbuscular mycorrhizal fungus. Fungal Biology 123: 732-744. doi: 10.1016/j.funbio.2019.06.009.
Luginbuehl, L.H., Menard, G.N., Kurup, S., Van Erp, H., Radhakrishnan, G.V., Breakspear, A., Oldroyd, G.E.D. and Eastmond, P.J. 2017. Fatty acids in arbuscular mycorrhizal fungi are synthesized by the host plant. Science 356: 1175-1178. doi: 10.1126/science.aan0081.

Maia, L.C. and Yano-Melo, A.M. 2001. Germination and germ tube growth of the arbuscular mycorrhizal fungi Gigaspora albida in different substrates. Braz. J. Microbiol. 32: 281-285.

Mosse, B. 1959. The regular germination of resting spores and some observations on the growth requirements of an Endogone sp. causing vesicular-arbuscular mycorrhiza. Trans. Bri. Mycol. Soc. 42: 273-286.

Mosse, B. and Hepper, H. 1975. Vesicular-arbuscular mycorrhizal infections in root organ cultures. Physiol. Plant Pathol. 5: 215-223. doi: 10.1016/0048-4059(75)90088-0.

Pawlowska, T.E., Douds, D.D. and Charvat, I. 1999. In vitro propagation and life cycle of the arbuscular mycorrhizal fungus Glomus etunicatum. Mycol. Res. 103: 1549-1556. doi: 10.1017/S095375629900 8801 .

Phillips, J.M. and Hayman, D.S. 1970. Improved procedures for clearing roots and staining parasitic and vesicular arbuscular mycorrhizal fungi for rapid assessment of infection. Trans. Bri. Mycol. Soc. 55: 158-161.

Smith, S.E. and Read, D.J. 2008. Mycorrhizal Symbiosis. San Diego: Academic Press.

Tahir, D. 2003. In vitro culture of arbuscular mycorrhizal fungi: advances and future prospects. Afr. J. Biotechnol. 2 (12). 10.5897/AJB2003.000-1128.

Voets, L., De La Providencia ,I.A., Fernandez, K., Ijdo, M., Cranenbrouck, S. and Declerck, S. 2009. Extraradical mycelium network of arbuscular mycorrhizal fungi allows fast colonization of seedlings under in vitro conditions. Mycorrhiza 19: 347- 356 . 